\title{
A Decisão sobre Investimento em Capital Humano em um Arranjo Produtivo Local (APL): Uma Abordagem Teórica
}

\author{
Carlos Eduardo Lobo e Silva*, Geoffrey J. D. Hewings ${ }^{\dagger}$
}

\footnotetext{
Conteúdo: 1. Introdução; 2.0 Modelo ; 3. Equilíbrios; 4. Efeitos sobre o Bem-Estar Advindos da Intervenção do Governo; 5. Conclusões.

Palavras-chave: Capital Humano, Treinamento e Arranjo Produtivo Local (APL).

Códigos JEL: D21, R12, J24 .
}

Partindo dos conceitos de treinamento geral e específico propostos por Gary Becker, este artigo propõe um modelo para analisar o investimento em capital humano durante o processo de desenvolvimento dos arranjos produtivos locais (ALPs). $O$ trabalho incorpora em sua análise os efeitos negativos advindos do comportamento oportunista das firmas aglomeradas, empiricamente identificados na literatura recente, e os efeitos positivos das economias de localização e urbanização. Os resultados - testáveis e com implicações de políticas públicas - mostram que tamanhos diferentes de APL e da economia na qual ele está inserido podem levar as firmas a diferentes equilíbrios.

The main objective of this work is to analyze the investment in human capital in the development of clusters. The theoretical model uses the concepts of general and specific training proposed by Gary Becker to formalize the tension between the negative effects coming from the opportunistic behavior, empirically identified by the literature, and the positive effects of urbanization and location economies. The results show how cluster sizes, city sizes, and the magnitude of the impact of training on the worker productivity may determine different equilibria.

\section{INTRODUÇÃO}

A aglomeração de empresas cujos processos produtivos são similares ou complementares traz benefícios aos seus integrantes, não só pela possibilidade de aumentar o poder de barganha do conjunto de empresas nas negociações com seus fornecedores e clientes, mas também porque permite a interação

* Pontificia Universidade Católica do Rio Grande do Sul (PUC-RS), Porto Alegre, Rio Grande do Sul, Brasil. E-mail: carlos . silva@ pucrs.br

†University of Illinois at Urbana-Champaign, Urbana, Illinois, USA. E-mail: hewings@uiuc .edu 
entre os agentes envolvidos no processo produtivo, o que, por sua vez, gera um transbordamento de conhecimento a todas as firmas aglomeradas. Estes efeitos positivos da aglomeração vêm sendo bastante estudados pela literatura, apesar da dificuldade em quantificá-los. ${ }^{1}$

Esta interação entre os agentes e a consequente absorção de conhecimentos adquiridos por outras firmas trazem a esta questão dois aspectos importantes. O primeiro é que o fluxo de informação e, principalmente, a capacidade de assimilação deste conhecimento podem ser afetados pelo nível de qualificação dos agentes envolvidos, ou seja, o estudo formal e o aperfeiçoamento técnico dos trabalhadores contribuem para uma maior assimilação do conhecimento trocado (Moretti, 2004, Yamamura et alii, 2003, Acemoglu, 2002). Além disso, uma empresa cujos vizinhos possuem processos produtivos semelhantes corre permanentemente o risco de perder seu funcionário treinado para uma outra empresa do mesmo Arranjo Produtivo Local (APL). A possibilidade de haver um comportamento oportunista por parte das empresas aglomeradas pode gerar uma espécie de seleção adversa: apenas as empresas com processos menos produtivos e eficientes e com trabalhadores menos qualificados têm incentivo a se aglomerar, enquanto aquelas mais eficientes se isolam das suas semelhantes (Shaver e Flyer, 2000, Brunello e De Paola, 2008).

Na literatura sobre o investimento em capital humano, ressalta-se o fato das empresas que investem em treinamento não terem qualquer garantia que irão se beneficiar plenamente do aumento da produtividade dos seus trabalhadores, uma vez que seus funcionários podem mudar de emprego após receberem o treinamento. Os futuros empregadores, portanto, podem capturar parte do aumento de produtividade (Becker, 1964, Acemoglu, 1997, Acemoglu e Pischke, 1998, 1999, Shaver e Flyer, 2000).

Em sua análise, Becker (1964) define treinamento geral e treinamento específico. Segundo ele, "General training is useful in many firms besides those providing it [...] 'Perfectly general' training would be equally useful in many firms and marginal product would rise by the same extent in all of them" (p. 33-34). Note, no entanto, que a definição de Becker condiciona o tipo de treinamento à presença de outras empresas que possam utilizar as habilidades dos trabalhadores treinados. Portanto, a implicação importante para a análise de investimento em capital humano nos processos de desenvolvimento dos APLs é justamente o fato de que são, em última instância, os vizinhos que determinam o tipo de treinamento oferecido pela firma em questão. Desta forma, um treinamento que se inicia como específico pode se tornar geral na medida em que novas empresas com processos de produção similares se instalam na mesma região.

Embora a estratégia de promover o desenvolvimento econômico regional através do fortalecimento dos APLs parece ter se tornado muito popular, ${ }^{2}$ relativamente pouca atenção tem sido dada à questão do investimento ótimo em capital humano por parte dos integrantes dos APLs. O presente modelo mostra que o investimento na qualificação da mão-de-obra pode ser reduzido como consequência do desenvolvimento do cluster e este equilíbrio sub-ótimo só será superado se uma terceira parte, especializada em treinamento, entrar no mercado regional em questão e oferecer seus serviços a todos os trabalhadores. Pelo fato da atividade de treinamento apresentar custos fixos, esta terceira parte (chamada aqui de instituição de ensino) entrará no mercado apenas quando o número de demandantes for suficientemente grande para que a diluição dos custos fixos permita que a instituição de ensino (IE) cobre preços compensadores para as duas partes.

Assim, este modelo tenta capturar a tensão entre os efeitos positivos da aglomeração - economias de localização e de urbanização - amplamente discutido na literatura e o efeito negativo, empiricamente mostrado nos trabalhos de Shaver e Flyer (2000) e Brunello e De Paola (2008).

\footnotetext{
${ }^{1}$ Veja, por exemplo, Gordon e McCann (2005), Glaeser et alii (1992), Henderson et alii (1995) e Rosenthal e Strange (2004).

${ }^{2}$ A este respeito, vale mencionar o comentário de Martin e Sunley (2003): "clusters, it seems, have become a world-wide fad, a sort of academic and policy fashion item" e de Steiner (2002) também sobre APLs: "the discreet charm of being obscure objects of desire".
} 
O trabalho está dividido em três seções, além desta Introdução. Na Seção 2, o modelo é construído. Na seção seguinte, os equilíbrios de mercado são apresentados. A Seção 4 analisa possíveis efeitos da intervenção do governo, enquanto as Conclusões do trabalho fecham o artigo na quinta seção.

\section{O MODELO}

O estudo dos APLs exige, como primeiro passo, uma definição do que vem a ser um arranjo produtivo local. Esta tarefa não é trivial. ${ }^{3}$ Para os objetivos deste trabalho, APLs devem ser entendidos como agrupamentos de firmas que apresentam as seguintes características:

(1) os processos de produção são suficientemente parecidos de tal forma que as habilidades adquiridas em treinamento que sejam úteis para uma firma do APL também serão para às demais pertencentes ao APL e

(2) as firmas estão localizadas suficientemente próximas umas das outras para que os trabalhadores tenham mobilidade (embora, não perfeita) entre elas.

A construção do modelo segue a idéia proposta por Becker (1964), incorporando pressupostos e conclusões de Acemoglu (1997) e Acemoglu e Pischke $(1998,1999)$. As empresas adotam uma função de produção de Leontief e são formadas pelo proprietário, fornecedor do capital físico, e por um trabalhador. As empresas e os trabalhadores são neutros ao risco.

Num mercado de trabalho em que os agentes não têm mobilidade perfeita, como é o caso do presente modelo, as empresas pagam parte da formação, mesmo quando as habilidades adquiridas possam ser capturadas por outras empresas (Acemoglu e Pischke, 1998, 1999).

Mas, ao contrário dos modelos que discutem o investimento em treinamento, aqui o treinamento será mais específico ou mais geral dependendo apenas do número relativo de empresas pertencentes ao APL que treinam seus funcionários, sem depender das especificidades do treinamento em si. Dessa forma, haverá apenas um 'tipo' de treinamento fornecido pelas firmas, que será útil a todas as empresas do APL e apenas a elas. Além disso, a variável "treinamento" é discreta, ou seja, as empresas não decidem quanto treinar; decidem apenas se oferecerão ou não treinamento.

Vale aqui mencionar um ponto importante: este trabalho não pretende entender as razões de crescimento ou declínio do APL; ao contrário, o modelo analisa as decisões de investimento em capital humano para diferentes níveis dados de desenvolvimento do cluster e seu tamanho em relação à economia como um todo.

O jogo se passa dentro de uma economia com $(M+N)$ firmas e uma Instituição de Ensino (IE), ${ }^{4}$ sendo que apenas $N$ firmas pertencem ao APL a ser estudado. A IE e as $N$ firmas do APL são os agentes que tomam decisões estratégicas neste jogo de três períodos (Figura 1 ). $O$ jogador a fazer 0 primeiro movimento é a IE, que pode ou não entrar no mercado. No segundo período, as $N$ firmas jogam simultaneamente, decidindo se treinam ou não seus funcionários e formalizam a decisão com um contrato incompleto, que estabelece ainda salários e a parcela do treinamento que será pago pelo trabalhador. O contrato não impede o trabalhador de abandonar o seu posto e nem a empresa de despedi-lo no fim deste período, como proposto em Acemoglu (1997).

No período final, após receber o treinamento, os trabalhadores poderão encontrar um novo empregador que esteja disposto a pagar salários mais elevados e, neste caso, trabalhador e novo empregador iniciariam um processo de negociação. A procura por um novo emprego não gera nenhum custo ao

\footnotetext{
${ }^{3}$ Sobre o debate a respeito das definições de APL, veja Steiner (2002), Martin e Sunley (2003) e Feser e Sweeney (2000).

${ }^{4}$ Dá-se o nome de Instituição de Ensino de maneira genérica, pois não é intenção deste trabalho escolher uma modalidade de ensino, entre cursos técnicos, superiores de curta duração ou superior tradicional. O fundamental aqui é que as $N$ firmas do APL, e apenas elas, se beneficiem do conhecimento e das habilidades adquiridas no curso oferecido pelo IE, enquanto as demais $M$ firmas desta economia demandam outros cursos não analisados aqui.
} 
Figura 1: Jogo em três períodos

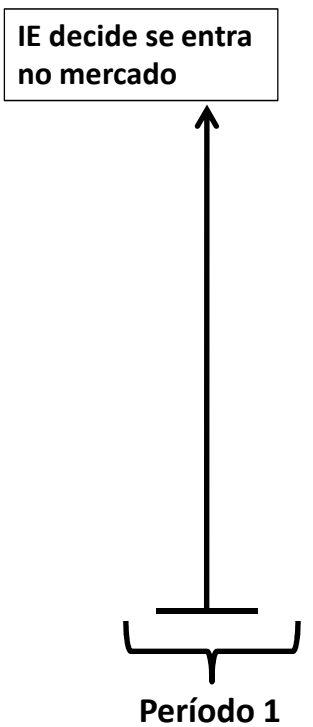

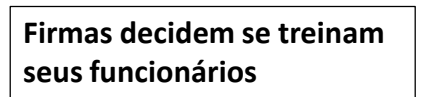

seus funcionários

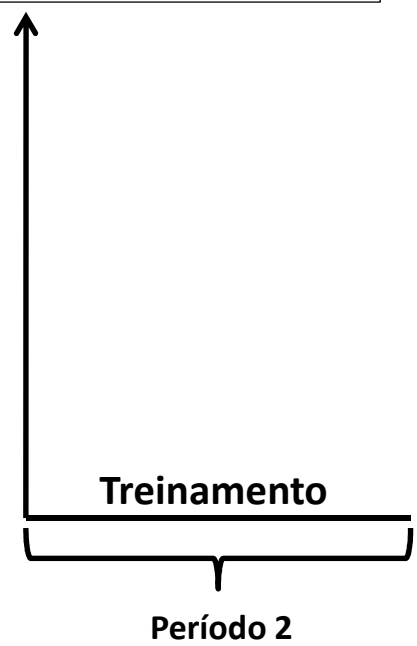

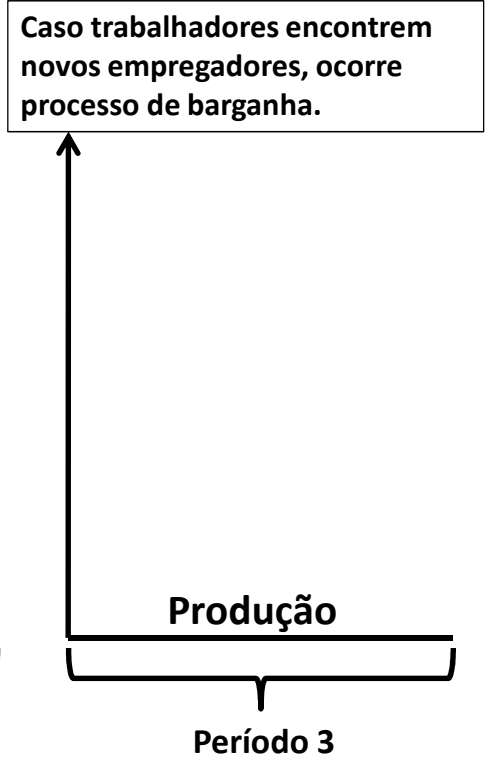

trabalhador ou à firma. Por outro lado, se o encontro entre o trabalhador treinado e o novo empregador não acontecer, será a firma que forneceu treinamento quem se beneficiará do aumento de produtividade de seu funcionário.

Os resultados mostram que o equilíbrio será a IE não entrar no mercado e todas as firmas treinarem seus trabalhadores quando $N$ for suficientemente pequeno relativamente ao tamanho da economia $(N+M)$. A partir do momento em que o número de firmas alcança um nível intermediário, o equilíbrio será a IE não entrar no mercado e as firmas não treinarem mais seus trabalhadores, caso a concentração de firmas aumente demasiadamente a probabilidade de uma firma que treinou seu funcionário perdê-lo para uma competidora oportunista. Finalmente, quando o número de firmas supera o estágio intermediário, a IE entra no mercado e todos os trabalhadores passam a ser treinados fora do local de trabalho (off-job training). Como será visto em breve, neste modelo, as firmas seguirão sempre estratégias dominantes. No equilíbrio intermediário, em que não há treinamento, o equilíbrio reproduz o dilema do prisioneiro, em que estratégias dominantes levam a um equilíbrio sub-ótimo.

A primeira hipótese considerada assume que a IE apresenta apenas custos fixos $(\mathrm{Cie})$ e incorre nesses custos assim que decide entrar no mercado. A instituição entrará no mercado se e somente se sua receita puder ser superior ao seu custo. Como mencionado, no segundo período, as firmas jogam 
simultaneamente, decidindo se treinam ou não seus funcionários. Normalizam-se em zero o salário de um trabalhador não treinado e a receita que este trabalhador gera para a firma.

Assim, podemos definir os payoffs esperados das firmas, que treinam $(t)$ e que não treinam $(n t)$ seu trabalhador, para o segundo e terceiro períodos:

$$
\begin{gathered}
U^{t}=-(C-k)+(1-l)(S) \\
U^{n t}=g S(1-\beta)
\end{gathered}
$$

Na Equação 1, os dois primeiros termos representam o custo total do treinamento $(C)$ e a parcela do custo do treinamento pago pelo trabalhador $(k)$. Note que o custo de treinamento $(C)$ não define se ele ocorre dentro da firma ou numa IE. Tem-se que:

$$
C=\min \left\{\bar{C},\left(\frac{C i e}{n}+\xi\right)\right\}
$$

Onde $\bar{C}$ é o custo do treinamento interno, $\xi$ é o lucro da IE por funcionário treinado e $n$ é o número total de trabalhadores matriculados. Adicionalmente, assume-se que o custo fixo da IE é maior que o custo da firma de treinar um trabalhador:

$$
\text { Cie }>\bar{C}
$$

Esta hipótese parece razoável em função da presença de ganhos de escopo: a firma já conta com equipamentos e infra-estrutura próprios do seu processo de produção que podem ser utilizados nos cursos de capacitação, o que o torna mais barato do que no caso da IE ter apenas um aluno.

Para a determinação do seu payoff esperado, as empresas formam expectativas sobre a probabilidade de perder seu trabalhador treinado no último período $(l)$, caso treine-o no segundo período, e sobre a probabilidade de tirar um trabalhador treinado de uma concorrente no último período $(g)$, caso não treine seu trabalhador no segundo período. Como será visto, estas probabilidades serão resultados das escolhas das firmas. $S$ é o ganho da empresa no terceiro período por ter um trabalhador treinado; ${ }^{5}$ enquanto $S \beta$ é a parcela do excedente perdida no processo de barganha com o novo trabalhador $(0<\beta<1)$, caso a empresa em questão tenha atraído um trabalhador treinado de outra firma.

Quanto ao poder de barganha dos trabalhadores, ele ocorre apenas se duas condições já mencionadas forem satisfeitas:

(1) eles foram treinados no segundo período e

(2) encontram novo empregador que pretende contratá-los para o terceiro período.

De qualquer forma, os trabalhadores levam em conta este possível ganho futuro e, por esta razão, podem concordar em pagar parte do treinamento, desde que os seus ganhos esperados em valor presente não sejam menores do que os ganhos dos trabalhadores não treinados. Portanto, por hipótese, o retorno esperado das firmas incorpora todo excedente gerado pelo treinamento e não há nenhuma razão para as firmas pagarem uma parte do treinamento maior do que aquela que iguala os ganhos esperados dos

\footnotetext{
${ }^{5}$ Já trazido a valores do período anterior.
} 
trabalhadores com e sem treinamento. ${ }^{6}$ Assim, como os salários dos dois períodos são normalizados em zero, pode-se determinar $k$ como: $^{7}$

$$
\begin{gathered}
0=-k+l^{\exp t r a b} \beta S \\
k=l^{\exp t r a b} \beta S
\end{gathered}
$$

Substituindo $k$ na Equação 2, chega-se a:

$$
U^{t}=-C+S\left(1-l+l^{\exp t r a b} \beta\right)
$$

Como o trabalhador leva em consideração a probabilidade de encontrar uma outra empresa com a qual possa barganhar um melhor salário para o período 3, quanto maior esta probabilidade, mais o treinamento terá um caráter geral e o trabalhador estará disposto a pagar por ele. A hipótese simplificadora assumida aqui é que a expectativa do trabalhador sempre se confirma em equilíbrio $\left(l^{\exp t r a b}=l\right)$.

Como condição de existência para o treinamento interno, note que, no caso do futuro APL contar apenas com a firma $j$, o treinamento tem caráter específico e a probabilidade de perder este trabalhador para uma concorrente $(l)$ é zero. Assim:

$$
-\bar{C}+S>0
$$

O que implica em:

$$
S>\bar{C}
$$

Portanto, como condição inicial para haver investimento em treinamento, o retorno do treinamento tem que ser maior que seu custo. Isto é o que está garantido na condição 9, que é assumida por hipótese no presente modelo. Se o treinamento não for vantajoso para a empresa nessas circunstâncias, ele nunca o será.

Por outro lado, deve-se ter aqui o seguinte cuidado: se $C$ estiver abaixo de $k$, o trabalhador estará pagando mais do que o custo do treinamento. Em outras palavras, a firma cobra o treinamento integralmente do trabalhador e ainda diminui seu salário pelo enorme ganho futuro que este trabalhador terá com o treinamento. Por causa da diminuição do salário, o treinamento seria sempre desejável para a firma, mesmo no caso dela ter como certa a perda deste trabalhador no período seguinte. Porém, este caso claramente distorce a vocação da firma, que maximizaria seu lucro através da venda de treinamento e não via aumento de produtividade. Para se eliminar a situação descrita, assume-se que a seguinte condição é satisfeita:

$$
\bar{C}>\beta S
$$

\footnotetext{
${ }^{6}$ Diferentemente das hipóteses assumidas aqui, outras poderiam ser consideradas para enriquecer o modelo. As empresas que perderam seus trabalhadores treinados poderiam ter a chance de contratar outro trabalhador treinado. Porém, isso geraria mais rodadas de contratação/perda, o que aumentaria a complexidade matemática do modelo. Alternativamente, poderíamos considerar $(l)$ como sendo a probabilidade de perder um trabalhador treinado, sem conseguir reposição à altura. Outra possibilidade seria permitir ao trabalhador iniciar um leilão entre a empresa original e a nova pretendente. Certamente, esse aspecto traz novas e interessantes análises, além, e como consequência, de transferir uma parte do excedente do treinamento para o trabalhador. Finalmente, a firma original poderia oferecer combinações de treinamento e salário para aumentar suas chances de segurar o trabalhador treinado. Entretanto, a existência de um excedente positivo - independente do valor - sempre abrirá espaço para o comportamento oportunista de outras firmas que dividiriam o excedente com o trabalhador.

${ }^{7}$ Os trabalhadores não são consideramos jogadores neste modelo. Como não possuem nenhum poder de mercado antes do treinamento, eles apenas seguem uma regra (Equação 6) que determina o quanto eles estariam dispostos a pagar pelo treinamento para que seu ganho esperado não seja inferior ao ganho dos trabalhadores não treinados.
} 
Enquanto a condição 9 garante a possibilidade de o treinamento ser desejável, assumindo um retorno líquido positivo quando não há comportamento oportunista, a condição 10 garante a possibilidade de o treinamento ser indesejável, assumindo que o custo total do treinamento é maior que o ganho esperado do trabalhador.

\section{EQUILÍBRIOS}

Um equilíbrio de Nash deste jogo será constituído por um conjunto de estratégias $\sigma\left(\sigma_{i e}, \sigma_{1}, \sigma_{2}, \ldots, \sigma_{N}\right)$ tal que, dados os valores de $S, N, M, C i e, \beta, \xi$ e $\bar{C}$, as condições 11 e 12 abaixo sejam satisfeitas:

$$
U_{j}\left(\sigma_{i e}, \sigma_{-j}, \sigma_{j}\right) \geq U_{j}\left(\sigma_{i e}, \sigma_{-j}, \sigma_{j}^{\prime}\right)
$$

para todo $\sigma_{j}^{\prime}$ pertencente ao conjunto de estratégias possíveis da firma $j$ e para todo $j \in(1, \ldots, N)$.

$$
U_{i e}\left(\sigma_{i e}, \sigma_{1}, \cdots, \sigma_{N}\right) \geq U_{i e}\left(\sigma_{i e}^{\prime}, \sigma_{1}, \cdots, \sigma_{N}\right)
$$

para todo $\sigma_{i e}^{\prime}$ pertencente ao conjunto de estratégias possíveis da IE.

As firmas tomarão suas decisões baseadas nas suas expectativas sobre as probabilidades $l$ e $g$. A construção destas probabilidades está, por sua vez, baseada na expectativa da firma quanto às decisões das demais firmas do APL. Inicialmente, cada firma conhece $N$ e $M$. Dada a imperfeita mobilidade dos trabalhadores, a firma $j$ constrói suas probabilidades esperadas como descrito abaixo:

$$
\begin{aligned}
& l_{j}^{e}\left(M, N, x_{j}^{e}\right)=\frac{N-1-x_{j}^{e}}{M+N-1} \\
& g_{j}^{e}\left(M, N, x_{j}^{e}\right)=\frac{x_{j}^{e}}{M+N-1}
\end{aligned}
$$

Onde $l_{j}$ é a probabilidade de um trabalhador treinado pela firma $j$ encontrar um novo empregador no período 3; enquanto, se a firma $j$ não treinar seu trabalhador no segundo período, $g_{j}$ representa a probabilidade desta firma conseguir atrair para o período $3 \mathrm{um}$ trabalhador treinado por outra firma. Finalmente, $x_{j}^{e}$ corresponde à expectativa da firma $j$ em relação ao número de firmas do APL que treinarão seus trabalhadores no segundo período. Portanto, os valores de fato de $l$ e $g$ serão resultados do equilíbrio do jogo, pois dependem do número de firmas que decidem treinar seus trabalhadores.

Levando-se em conta as expectativas das firmas e utilizando-se as Equações 2 e 7, pode-se definir o problema de maximização da firma $j$ como sendo:

Maximizar $U_{j}^{e}=\max \left\{-C+S\left(1-l_{j}^{e}+l_{j}^{e} \beta\right), S(1-\beta) g_{j}^{e}\right\}$.

Ou seja, a firma deve escolher o payoff esperado de uma das alternativas: treinar ou não seu trabalhador.

Proposição 1. Dados $S, \beta, M, N$ e $C$, as firmas terão uma estratégia dominante que independe das suas expectativas a respeito de quantas firmas treinarão seus trabalhadores.

Prova. A firma $j$ treinará seu trabalhador se:

$$
\begin{gathered}
U_{j}^{t} \geq U_{j}^{m} \\
-C+S(1-l+l \beta) \geq S(1-\beta) g \\
-C+S-S\left(\frac{N-1-x_{j}^{e}}{M+N-1}\right)(1-\beta) \geq S\left(\frac{x_{j}^{e}}{M+N-1}\right)(1-\beta)
\end{gathered}
$$




$$
C \leq S\left[1-\left(\frac{N-1}{M+N-1}\right)+\left(\frac{N-1}{M+N-1}\right) \beta\right]
$$

Portanto, se e somente se o custo do treinamento for menor que a expressão definida em 18, que por sua vez não é função das expectativas da firma $j$, a firma $j$ oferecerá treinamento a seu trabalhador. Caso contrário, a firma não treinará seu trabalhador.

A consequência direta da Proposição 1 é que a decisão da firma $j$ independe não apenas da sua expectativa, mas também da decisão das demais firmas. Adicionalmente, uma vez que as firmas são idênticas, as decisões individuais das firmas serão as mesmas em equilíbrio. ${ }^{8}$

A IE entrará no mercado se e somente se as condições 18 e 19 forem satisfeitas:

$$
\frac{C i e}{n_{i e}^{e}}<\bar{C}
$$

Onde o denominador é a expectativa da IE quanto ao número de matriculados. No caso da condição 19 ser satisfeita, assume-se que a IE cobrará o seu custo acrescido de $\xi$, de tal forma que:

$$
\frac{C i e}{n_{i e}^{e}}<\frac{C i e}{n_{i e}^{e}}+\xi<\bar{C}
$$

Como mencionado, a condição 18 garante que, a este custo, o treinamento valha à pena, enquanto a condição 19 garante que o custo da IE por aluno é menor que o custo do treinamento interno, ou seja, as firmas estarão dispostas a oferecer treinamento, através da contratação do serviço da IE. Para resolver o jogo por indução retroativa, pode-se definir a estratégia da firma como descrito na Tabela 1:

Tabela 1: Estratégia das firmas

\begin{tabular}{|c|c|c|}
\hline & Condição 19 satisfeita & Condição 19 não satisfeita \\
\hline Condição 18 satisfeita & Treina na IE & Treina internamente \\
\hline Condição 18 não satisfeita & Não treina & Não treina \\
\hline
\end{tabular}

Assim, os payoffs das firmas e da IE, além do excedente gerado pelo treinamento para cada resultado desse jogo estão representados na Tabela 2 . Levando em conta a estratégia da firma representativa definida acima, a IE não entrará no mercado caso a condição 18 e/ou a condição 19 não sejam satisfeita, evitando um payoff de (-Cie) e garantindo um payoff igual a zero.

Um equilíbrio possível é aquele em que, dados $S, N, M, C i e, \beta, \xi$ e $\bar{C}$, as condições 18 e 19 são satisfeitas: a IE entra no mercado e a firma representativa treina seus funcionários na IE, fazendo com que $n_{i e}^{e}=N$.

Já se a condição 18 é satisfeita, mas a condição 19 não, a IE não entra no mercado e a firma representativa treina seus $N$ funcionários internamente.

Finalmente, no caso da condição 18 não ser satisfeita para os valores de $S, N, M, C i e, \beta, \xi$ e $\bar{C}$, a IE não entra no mercado e a firma representativa não treina seus funcionários; resultado sub-ótimo que reproduz o dilema do prisioneiro.

\footnotetext{
${ }^{8}$ Note que as variáveis $l$ e $g$ nunca assumirão valores positivos em equilíbrio porque as firmas do APL tomarão a mesma decisão sobre treinamento. Assim, a probabilidade da firma $j$, que não treinou seu funcionário, atrair um funcionário treinado para $o$ período 3 é zero porque, neste caso, nenhuma firma do APL terá treinado seu funcionário $(g=0)$. A probabilidade da firma $j$, que treinou seu funcionário, perdê-lo para outra firma do APL que não treinou seu funcionário no período 2 também será zero, porque, neste caso, todas as firmas do APL terão treinado seus funcionários $(l=0)$.
} 
Tabela 2: Payoffs e excedentes

\begin{tabular}{|c|c|c|c|}
\hline & Payoff da IE & $\begin{array}{c}\text { Payoff } \\
\text { individual }\end{array}$ & Excedente gerado \\
\hline $\begin{array}{c}\text { IE entra } \\
\text { Firmas treinam na IE }\end{array}$ & $N \xi$ & $S-$ Cie $/ N-\xi$ & $N S-$ Cie \\
\hline $\begin{array}{c}\text { IE não entra } \\
\text { Firmas treinam interinamente }\end{array}$ & 0 & $S-\bar{C}$ & $N(S-\bar{C})$ \\
\hline $\begin{array}{c}\text { IE não entra } \\
\text { Firmas não treinam }\end{array}$ & 0 & 0 & 0 \\
\hline $\begin{array}{c}\text { IE entra } \\
\text { Firmas não treinam }\end{array}$ & - Cie & 0 & - Cie \\
\hline $\begin{array}{c}\text { IE entra } \\
\text { Firmas treinam interinamente }\end{array}$ & - Cie & $S-\bar{C}$ & $N(S-\bar{C})-C i e$ \\
\hline
\end{tabular}

Proposição 2. Dados $S, \beta, M, \bar{C}$ e $C_{i e}$ e respeitadas as hipóteses 4, 9 e 10, as firmas sempre treinam seus funcionários internamente para $N$ suficientemente pequeno (não menor que 1) e sempre treinam seus funcionários na IE para $N$ suficientemente grande.

Prova. Para a prova da primeira, basta assumir $N=1$. Como a condição 4 garante que o retorno líquido do treinamento interno é positivo e a condição 9 garante que o custo de treinamento de um único funcionário é mais barato dentro da firma, pode-se concluir que, quando $N=1$, haverá treinamento interno.

A prova da segunda parte também é bastante simples: quando $N$ vai a infinito, no equilíbrio a condição 19 será satisfeita e a condição 18 se modifica para:

$$
0 \leq S \beta
$$

Como o custo de treinamento na IE agora é menor que o custo de treinamento interno e, levando em conta que a condição 10 é satisfeita, chega-se a conclusão que o equilíbrio será definido com a IE entrando no mercado e a firma representativa treinando os $N$ funcionários na IE.

Este resultado nos diz que, independente do tamanho da economia, tanto um APL com um número suficientemente pequeno de firmas quanto um APL com um número suficientemente grande de firmas treinarão seus funcionários.

Porém, um APL que se desenvolve em uma cidade com porte menor que o limite definido a seguir enfrentará um estágio em que as firmas não treinam seus trabalhadores e estabelecem o dilema do prisioneiro. Este resultado é formalizado pelo Proposição 3.

Proposição 3. Dados $\bar{C}, C i e, S$ e $\beta$, se $M, M^{*}=\frac{(\text { Cie } / \bar{C}-1)(\bar{C}-S \beta)}{(S-\bar{C})}$, então haverá $N$ positivo tal que, em equilíbrio, os trabalhadores não serão treinados.

Prova. Como definido anteriormente, haverá treinamento se a seguinte condição for satisfeita: $C \leq$ $S\left[1-\left(\frac{N-1}{M+N-1}\right)+\left(\frac{N-1}{M+N-1}\right) \beta\right]$.

o que significa dizer: 


$$
M \geq \frac{(N-1)(C-S \beta)}{(S-C)}
$$

Mas existe um $N^{*}$ que iguala o custo do treinamento interno com o custo médio da IE, ou seja:

$$
N^{*}=\frac{C i e}{\bar{C}}
$$

Então, se $M<\frac{(C i e / \bar{C}-1)(\bar{C}-S \beta)}{(S-\bar{C})}$ a condição 22 não será satisfeita para pelo menos um valor positivo de $N$. Portanto, qualquer APL que nasce em cidades do tamanho ou menor que passará por ao menos um momento em que suas firmas não treinarão seus trabalhadores.

0 resultado nos diz ainda que quanto menor o retorno do treinamento $(S)$, ou quanto maior o poder de barganha dos trabalhadores $(\beta)$, maior será $M^{*}$.

Combinando os resultados das Proposições 2 e 3, pode-se dizer que, para APLs que se desenvolvem em cidades cujas economias não são suficientemente grandes, a sequência dos equilíbrios será: treinamento interno ( $N$ pequeno), sem treinamento ( $N$ intermediário) e treinamento na IE ( $N$ grande).

\section{EFEITOS SOBRE O BEM-ESTAR ADVINDOS DA INTERVENÇÃO DO GOVERNO}

A intervenção do governo, através de subsídios à IE, subsídios às firmas que treinam seus trabalhadores ou até mesmo instalando uma IE gratuita, pode aumentar o excedente total da economia, na medida em que elimina ou diminui a ocorrência do equilíbrio indesejável de investimento sub-ótimo.

A Figura 2 traz as combinações entre o número de firmas do APL $(N)$ e o número de firmas nãopertencentes ao APL $(M)$ e os outcomes dos equilíbrios possíveis. ${ }^{9}$ Na área de treinamento interno, o número de firmas do APL é pequeno relativamente ao tamanho da economia, portanto, a dispersão é suficientemente grande e o risco de perder seu trabalhador treinado é suficientemente baixo para as firmas oferecerem treinamento interno. Para esta área, a IE não aparece no mercado, dado o baixo número absoluto de firmas do APL.

Na área em que não há treinamento, a concentração de empresas do APL em uma economia relativamente pequena faz com que as firmas não treinem seus funcionários. Note que o crescimento de $N$ a partir do momento em que o custo da IE por estudante passa a ser menor que o custo do treinamento interno (no caso, quando $N=50$ ) reduz ainda mais o custo de treinamento, até um ponto em que o treinamento é sempre vantajoso, independente do tamanho da economia $(\mathrm{Cie} / N<\mathrm{S} \beta)$.

Para não estender demasiadamente a análise, examina-se a seguir os efeitos de da implantação de uma IE gratuita (Figura 3). O governo só instala uma IE gratuita quando o custo total ( $\mathrm{Cie}$ ) for igual ou inferior ao excedente total gerado pelo treinamento $(S N)$. No caso simulado, esta situação ocorre quando $N$ iguala 40. No jogo descrito na seção anterior, o governo faria o primeiro movimento e, com a entrada da IE gratuita, a IE privada não entraria no mercado e as firmas treinariam seus trabalhadores.

Percebe-se pela Figura 3 que as firmas treinarão seus trabalhadores na IE gratuita se e somente se $N \geq 40$, independente do valor de $M$. Além disso, todas as combinações de $N$ e $M$ contidas na figura definida por ABDC passam a gerar um excedente positivo $(S N-C i e)$ com a entrada da IE gratuita.

\section{CONCLUSÕES}

Este trabalho procurou formalizar um efeito não desejável que a aglomeração de firmas pode gerar e que tem sido verificado pela literatura (Shaver e Flyer, 2000, Brunello e De Paola, 2008): o comportamento oportunista permite às firmas absorver processos mais eficientes e atrair mão-de-obra mais

\footnotetext{
${ }^{9}$ Simulação usou os seguintes parâmetros: $C i e=2000 ; \bar{C}=40 ; \beta=0,4 ; S=50$.
} 
Figura 2: Estratégias adotadas pelas Firmas para $N$ e $M$

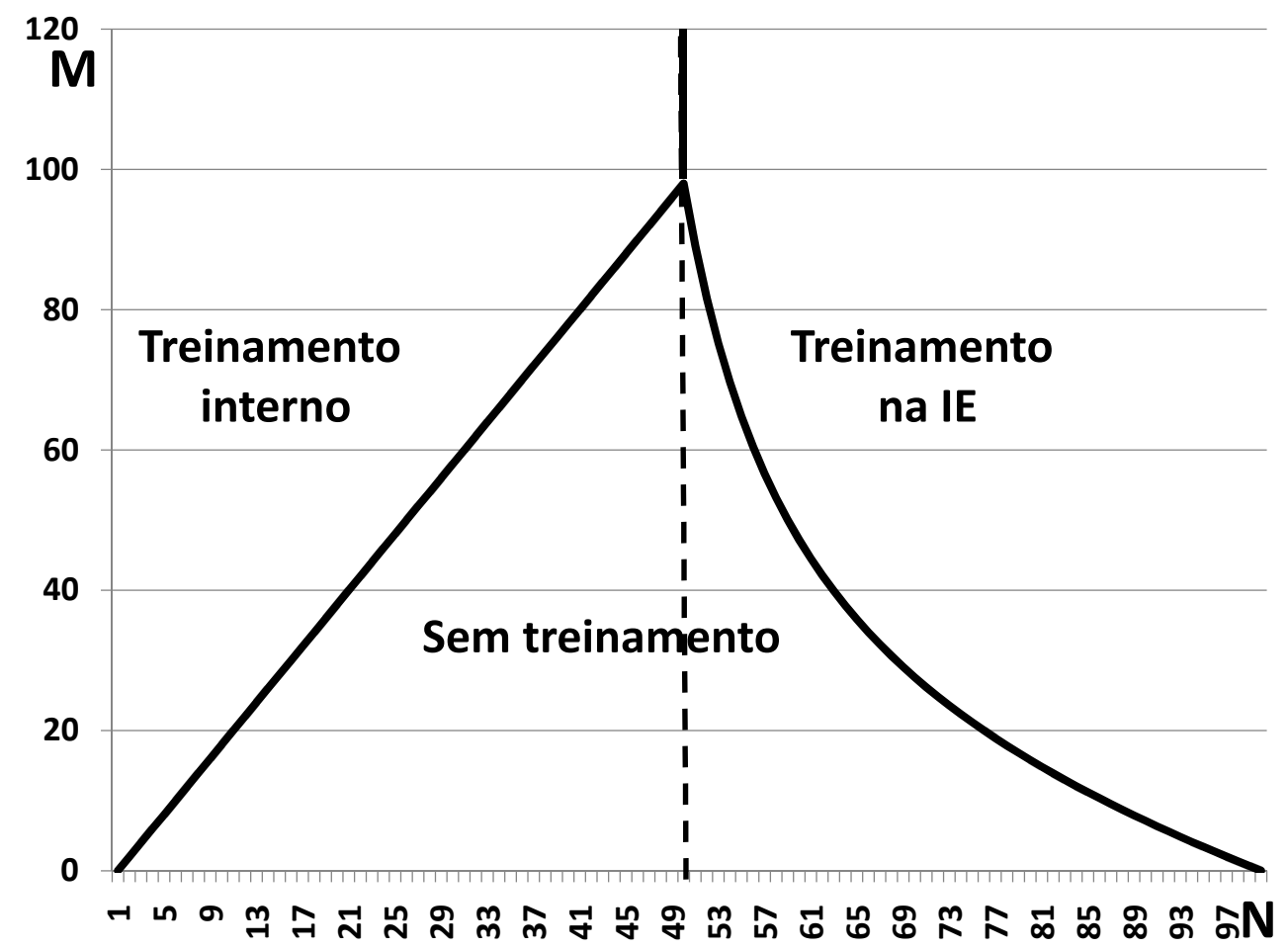

qualificada das firmas vizinhas, o que pode gerar um investimento abaixo daquele verificado sem aglomeração.

O modelo tem a possibilidade de combinar duas variáveis - tamanho do APL e tamanho da economia - e relacionar estas combinações com os diferentes equilíbrios quanto ao investimento em capital humano, não só do ponto de vista de investir ou não, mas também em relação ao local de treinamento.

Basicamente, os resultados finais do artigo mostram que as aglomerações podem chegar a três resultados distintos:

(1) os trabalhadores de APLs com muitas firmas inseridas em economias pequenas não receberão treinamento;

(2) os trabalhadores de APLs com poucas firmas localizados em cidades de médio e grande porte receberão treinamento dentro das empresas e

(3) trabalhadores de grandes APLs localizados em grandes centros receberão treinamento oferecido externamente às suas firmas.

Vale ressaltar que em nenhum dos equilíbrios possíveis do modelo os trabalhadores pagam pelo seu treinamento, pois nenhuma ou todas as firmas treinam seus trabalhadores e, em equilíbrio, não haverá 
Figura 3: Equilíbrios com a presença da IE gratuita

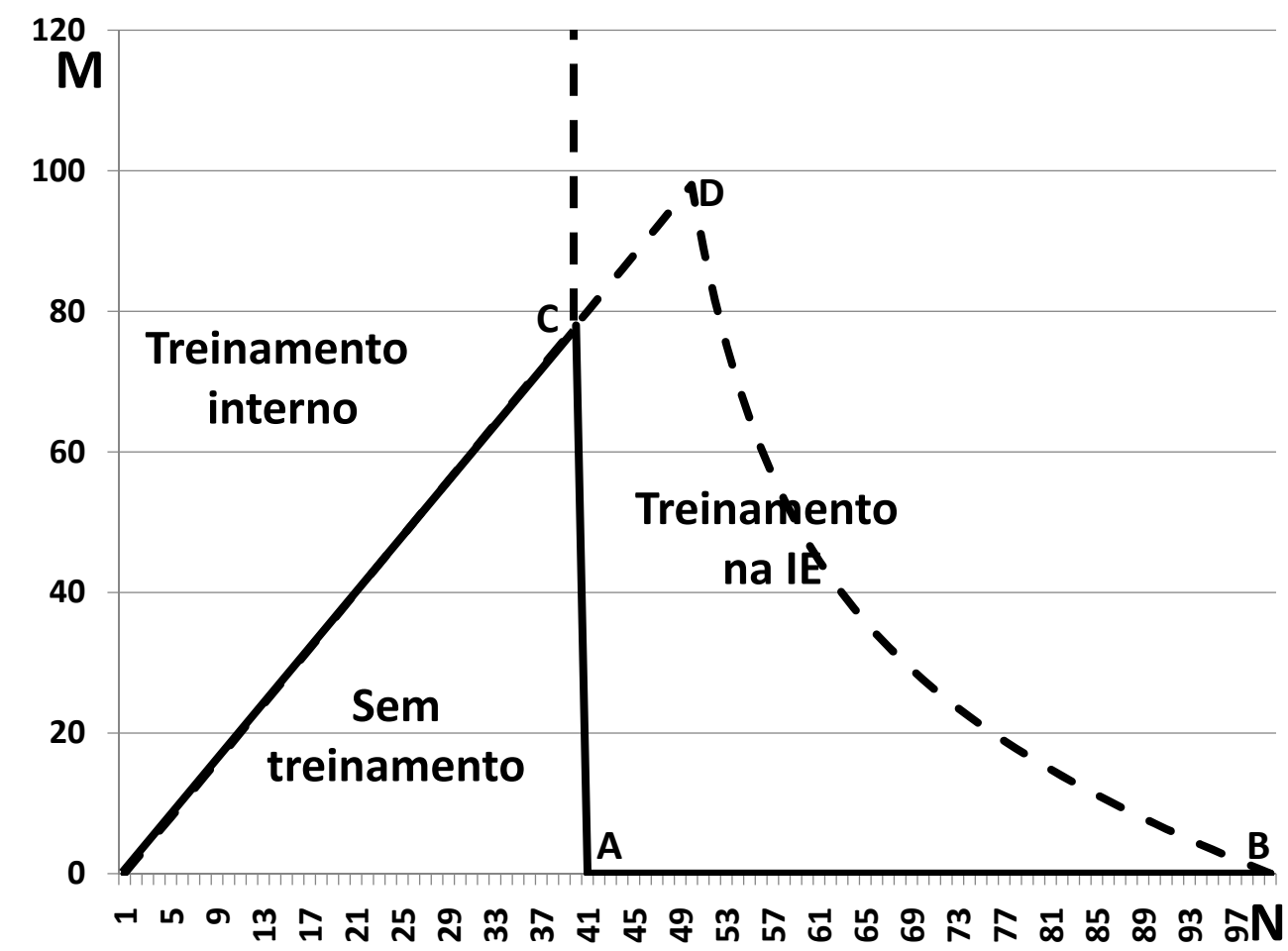

comportamento oportunista. Este resultado é compatível com as conclusões de Hansson (2008). A partir de uma revisão de estudos sobre o tema, o autor mostra que, normalmente, são as empresas que pagam pelo treinamento dos seus trabalhadores, mesmo quando as habilidades adquiridas são úteis às concorrentes. O mesmo autor afirma ainda que há pouca pesquisa a respeito dos efeitos da aglomeração sobre a disposição das firmas em treinar seus funcionários.

Finalmente, baseado nos resultados teóricos deste artigo e nos excedentes gerados pelo treinamento, a principal sugestão de política pública seria subsidiar IE nas regiões em que as firmas e a IE chegam a um equilíbrio sub-ótimo.

Evidentemente, a análise do modelo e de seus resultados apresentados aqui deve levar em conta as limitações advindas de suas hipóteses restritivas. Testar os resultados e/ou relaxar as hipóteses mais restritivas são extensões possíveis do trabalho. Caso a intenção seja ressaltar o papel das relações entre trabalhadores e firmas e do poder de barganha de cada parte na decisão sobre qualificação da mão-deobra, o comportamento dos trabalhadores merece um tratamento menos restritivo. 


\section{BIBLIOGRAFIA}

Acemoglu, D. (1997). Training and innovation in an imperfect labor market. Review of Economic Studies, 64:445-464.

Acemoglu, D. (2002). Technical change, inequality and the labor market. Journal of Economic Literature, 40(1):7-72.

Acemoglu, D. \& Pischke, J. S. (1998). Why do firms train? Theory and evidence. Quarterly Journal of Economics, 113:79-119.

Acemoglu, D. \& Pischke, J. S. (1999). Beyond Becker: Training in imperfect labor market. Economic Journal, 109:112-142.

Becker, G. (1964). Human Capital. The University of Chicago Press, Chicago.

Brunello, G. \& De Paola, M. (2008). Training and economic density: Some evidence form Italian provinces. Labour Economics, 15:118-140.

Feser, E. \& Sweeney, S. (2000). A test for the coincident economic and spatial clustering of business enterprises. Journal of Geographical Systems, 2:349-373.

Glaeser, E., Kallal, H., Scheinkman, J. A., \& Shleifer, A. (1992). Growth in cities. Journal of Political Economy, 100:1126-1152.

Gordon, I. \& McCann, P. (2005). Innovation, agglomeration and regional development. Journal of Economic Geography, 5:523-543.

Hansson, B. (2008). Job-related training and benefits for individuals: A review of evidence and explanations. OECD Education Working Paper 19.

Henderson, V., Kuncoro, A., \& Turner, M. (1995). Industrial development of cities. Journal of Political Economy, 103:1067-1090.

Martin, R. \& Sunley, P. (2003). Deconstructing clusters: Chaotic concept or policy panacea? Journal of Economic Geography, 3:5-35.

Moretti, E. (2004). Workers' education spillover and productivity: Evidence from plant-level production functions. American Economic Review, 94(3):656-690.

Rosenthal, S. \& Strange, W. (2004). Evidence on the nature and sources of agglomeration economies. In Henderson, J. V. \& Thisse, J. F., editors, Handbook of Urban and Regional Economics, pages 2119-2171. Elsevier.

Shaver, J. \& Flyer, F. (2000). Agglomeration economies, firm heterogeneity and foreign direct investment in the United States. Strategic Management Journal, 21:1175-1193.

Steiner, M. (2002). Clusters and networks: Institutional settings and strategic perspectives. In McCann, P., editor, Industrial Location Economics, pages 207-221. Elgar, Northampton, Massachusetts.

Yamamura, E., Sonobe, T., \& Otsuka, K. (2003). Human capital, cluster formation and international relocation: The case of the garment industry in Japan, 1968-98. Journal of Economic Geography, 3:3756. 